\title{
Targeting physical activity and nutrition interventions towards mothers with young children: a review on components that contribute to attendance and effectiveness
}

\author{
Marieke A Hartman ${ }^{1,2, *}+$, Karen Hosper $^{1}$ and Karien Stronks ${ }^{1}$ \\ 'Department of Public Health, Academic Medical Centre/University of Amsterdam, Amsterdam, \\ The Netherlands: ${ }^{2}$ Department of Epidemiology and Health Promotion, Public Health Service of Amsterdam, \\ Amsterdam, The Netherlands
}

Submitted 1 October 2009: Accepted 1 June 2010: First published online 16 July 2010

\begin{abstract}
Objective: To gain insight into intervention components targeted specifically to mothers of young children that may contribute to attendance and effectiveness on physical activity and healthy eating.

Design: Systematic literature searches were performed using MEDLINE, Embase and cited references. Articles were included if they evaluated the effectiveness of a lifestyle intervention to promote physical activity and/or healthy eating in an experimental design among mothers with young children (age 0-5 years). Data were extracted on study characteristics, intervention components targeted towards mothers with young children, attendance and effectiveness. Extracted data were analysed in a descriptive manner.

Results: Eleven articles describing twelve interventions met the inclusion criteria. Of the six studies that measured attendance, two reported high attendance. Embedding the intervention within routine visits to child health clinics seems to increase attendance. Three studies found significant effects on physical activity and three on healthy eating. Effective interventions directed at physical activity included components such as counselling on mother-specific barriers or community involvement in intervention development and implementation. One of the three interventions that effectively increased healthy eating had components targeted at mothers (i.e. used targeted motivational appeals).

Conclusions: The number of experimental intervention studies for promoting physical activity and healthy eating among new mothers is limited. However, useful first recommendations can be set for targeting interventions towards mothers, in particular for promoting attendance and physical activity. More insight is required about the need for targeting health promotion programmes at new mothers, especially of those directed at nutritional behaviour.
\end{abstract}

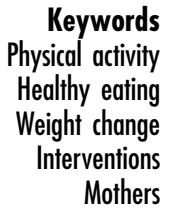

A decrease in physical activity during the transition into motherhood may explain the higher increase in weight gain among new mothers compared with non-mothers. A meta-analysis showed that mothers were less likely to be physically active than fathers and non-parents ${ }^{(8)}$. In particular, mothers of young children (under the age of 5 years) seem to be at risk for physical inactivity ${ }^{(9,10)}$. Changes in nutritional behaviour before and after pregnancy are found inconsistently ${ }^{(11-13)}$. However, this does not mean that there is no room left to improve nutritional behaviour among mothers. An unhealthy diet and a decrease in physical activity are both related to weight gain among mothers with young children ${ }^{(7,14,15)}$.

Preliminary findings of a recently published Cochrane review $^{(16)}$ extracted from six studies showed that among women recruited in the postpartum period (up to 12 months
† Correspondence address: Academic Medical Centre/University of Amsterdam, Department of Public Health, PO Box 22660, 1100 DD Amsterdam, The Netherlands. 
postpartum) a prescribed diet combined with structured exercise, or diet alone, compared with usual care, seemed to enhance weight loss ${ }^{(16)}$. However, this Cochrane review focused on the effect of a change in diet or exercise on change in weight without examining the factors that lead to behaviour change. In order to develop weight-loss programmes, it is useful to have insight into how these behaviours can be promoted.

In addition, it seems worthwhile to look at how mothers can be encouraged to attend such programmes. The years it takes to establish a young family involve a major life transition for women in terms of their social, occupational and biological lives ${ }^{(17)}$. Most mothers of young children experience some constraints, for example lack of time and energy, and the responsibilities of child care. These factors may influence their interest in and ability to attend interventions ${ }^{(18)}$.

Targeting nutrition and physical activity interventions to these mother-specific factors may enhance both their effectiveness and attendance rate. Therefore, the purpose of the present review is to gain insight into targeted intervention components which may contribute to the attendance and effectiveness of interventions promoting physical activity and/or healthy eating to mothers with young children $(0-5$ years).

\section{Materials and methods}

\section{Search strategy and data sources}

Intervention studies were identified through a structured electronic database search in OVID Embase and MEDLINE. The search strategy, shown in Table 1, included searching on words in the title or abstract and MeSH terms. The search was limited to articles with MeSH term 'human' (or 'humans' in MEDLINE) and articles published from 1997 to 2009.

\section{Selection criteria}

Studies eligible for inclusion were: intervention studies aimed at promotion of physical activity and/or healthy eating; the target group was mothers (aged $18+$ years) with young children (aged 0-5 years); the study design included a pre- and post-measurement among an intervention and a control group. Studies were excluded if the intervention was a prescribed diet or exercise programme with no attention paid to lifestyle change (e.g. sessions with prescribed exercise to achieve a certain percentage of the heart rate reserve for a certain amount of time). Also, studies were excluded if the study population consisted of mothers with mental health problems because this was considered to be a different subpopulation. Finally, studies were excluded if no information was available about the age of the children. An exception was made for participants of the Special Supplemental Nutrition Program for Women, Infants, and Children (WIC), since this programme provides food, nutrition counselling and access to health resources
Table 1 Search strategy

$\overline{\text { (physical activity OR exercise OR fruit OR vegetable OR fat intake }}$ OR carbohydrate intake OR fibre intake OR dietary intake OR weight loss OR weight control OR weight management OR weight reduction)

AND

(postpartum OR mother OR mothers OR lactating women OR WIC*)

AND

(intervention OR program OR randomized controlled trial OR community intervention trial OR treatment OR therapy OR effectiveness OR effect OR impact OR pilot study)

*WIC, Special Supplemental Nutrition Program for Women, Infants, and Children. The WIC programme provides food, nutrition counselling and access to health resources for low-income pregnant and postpartum women with children up to the age of 5 years in the USA (http://www. fns.usda.gov/wic/).

specifically for low-income pregnant and postpartum women with children up to the age of 5 years in the USA (http://www.fns.usda.gov/wic/).

\section{Procedure}

The titles and abstracts were assessed by the first author (M.A.H.). In cases of doubt the second author was consulted (K.H.). If a reference was considered to be relevant, the full paper was retrieved. Full papers were assessed against the review selection criteria. Reference lists of relevant articles were scanned. Extracted data included study characteristics, intervention characteristics, intervention components targeted at mothers, and reported intervention attendance and effectiveness. By intervention components targeted at mothers, we mean the intervention components adapted to the situation of mothers with young children. By attendance, we mean not only attendance at intervention classes but also exposure to the intervention in other ways (i.e. dose received).

Information on the characteristics of the studies was collected so that the quality and generalizability of the studies could be assessed. The following information about study characteristics was extracted: the country where the study was conducted, design (true experiment or quasi-experiment), description of the intervention and comparison group, response and attrition rate, and primary outcome measures.

Additionally, data were extracted separately for intervention components presumed to be related to attendance and effectiveness. Information on both kinds of results is important, since a low attendance or a low effectiveness will result in a low impact of the intervention. The results were analysed in a descriptive manner.

For attendance, intervention components targeted at mothers were summarized. Subsequently, the intervention components in studies with a low attendance were compared with those in studies with a high attendance. In addition, information was collected about possible explanations for non-attendance. 
For effectiveness on physical activity and healthy eating, intervention components specifically targeted at mothers were summarized, related to effectiveness (statistically significant effects or not) and additional information was collected on the possible explanations for their effectiveness. Furthermore, if key elements of a systematic development of interventions were used (use of formative research, theory, behavioural change strategies, evidence and targeting other characteristics than being a mother), these elements were then also summarized. Such elements should be taken into account when interpreting the results of the relationship between targeted components and the effectiveness of interventions because a systematic intervention development increases the likelihood of obtaining the intended positive effects ${ }^{(19)}$.

\section{Results}

\section{Study selection}

The initial search identified 1556 publications. After eliminating duplicates and reviewing the titles and abstracts of these publications, the total was reduced to forty-two. These forty-two articles were completely reviewed, after which thirty-one publications were excluded because they did not meet one or more of the inclusion criteria. The main reasons for exclusion were lack of a control group; a different outcome measurement than physical activity or nutritional behaviour; or because mothers of children above 5 years of age were included in the study. Moreover, four review articles were found, all describing studies which mainly investigated the relationship between weight-related behaviours and weight only using prescribed diet or exercise with no attention for lifestyle change ${ }^{(16,20-22)}$. Equally, two intervention studies were excluded for this reason. Finally, some articles seemed to report the results of the same study because they described the same intervention and the same number of participants. In one case, the article was chosen which described the effect evaluation ${ }^{(23)}$ instead of the feasibility study ${ }^{(24)}$. In the other two cases, articles were selected which evaluated the effect on actual health-related behaviour $^{(25,26)}$ instead of on the stages of change ${ }^{(27)}$ or purchasing of fresh fruit and vegetables ${ }^{(28)}$. After checking references no other relevant articles were found. Therefore, a total of eleven articles were eligible, describing twelve interventions (Table 2).

\section{Study characteristics}

The eligible studies differed on many characteristics (Table 3). Most of the studies were conducted in the $\mathrm{USA}^{(25,26,29,30,31,32,33)}$, two in Australia ${ }^{(34,35)}$, one in Canada $^{(36)}$ and one in Finland ${ }^{(23)}$. Four interventions were implemented in a clinical setting ${ }^{(23,31,33,35)}$, three in a community setting ${ }^{(34,36)}$ and five interventions were implemented within or alongside the $\mathrm{WIC}^{(25,26,29,30,32)}$. Three studies were quasi-experiments ${ }^{(23,26,35)}$ and eight true experiments ${ }^{(25,29-34,36)}$.
Six studies included only postpartum mothers with children up to the age of 1 year ${ }^{(23,26,31,33,35,36)}$, in contrast with the five other studies which included mothers of children up to 5 years ${ }^{(25,29,30,32,34)}$. Moreover, the study populations differed on socio-economic and ethnic composition. The American studies directed at WIC mothers mainly included a relatively high percentage of low-income women and women from minority groups ${ }^{(25,26,29,30,32)}$. Control groups consisted mainly of usual care $e^{(23,25,30)}$ or no intervention $^{(29,34,35)}$. The study population size varied from fortyfour to 3122 participants.

The variation in response rates was large, $30 \cdot 8 \%$ to $91 \cdot 2 \%$, but almost half of the studies gave no information about response rates. No information could be obtained about response rate for one study since respondents were recruited passively through a local community newspaper article on postnatal fitness ${ }^{(36)}$. In the other studies, respondents were recruited actively, i.e. were personally approached to participate in the study. Short-term attrition rates varied from $7 \cdot 6 \%$ to $31 \cdot 0 \%$.

Three interventions were directed at promoting healthy eating, physical activity as well as weight change ${ }^{(23,31,33)}$; four interventions were aimed at promoting healthy eating $^{(25,26,29,30)}$; and four at physical activity ${ }^{(32,34,35)}$. In all studies, nutritional behaviour was measured by selfreports; physical activity by self-reports or objective measurement (pedometer/accelerometer); and weight loss by self-reports or anthropometric measurements.

\section{Attendance}

Within the six studies that reported attendance, full attendance ranged from $9 \%$ to $92 \%$ (Table 4 ). In two studies ${ }^{(30,33)}$ subgroup analyses were performed. Older ( $>30$ years) and higher educated mothers were more likely to attend in both studies. In one study participants were more likely to be white $^{(33)}$, while in the other study there was no difference regarding attendance between ethnic groups ${ }^{(30)}$. Moreover, married $^{(33)}$, higher-income ${ }^{(33)}$ and unemployed ${ }^{(30)}$ mothers were more likely to attend compared with mothers who did not participate.

\section{Components within intervention studies reaching a low v. a bigh attendance}

Two studies succeeded in reaching a high attendance of mothers $^{(23,36)}$ (Table 4). The intervention of Kinnunen et $a l^{(23)}$ was embedded within routine visits to child health clinics, normally attended by $98 \%$ of the target population. This resulted in a $92 \%$ attendance to their intervention. Furthermore, Cramp and Brawley ${ }^{(36)}$ reached an attendance of $75 \%$. Their attempts involved conducting the intervention in a community-based fitness facility and providing child care for a nominal fee. Other interventions whereby child care was provided or an activity with mothers and children was organized did not result in high attendance ${ }^{(25,33,35)}$.

Moreover, several other approaches were used in order to increase attendance among mothers with young 
Table 2 Overview of interventions directed at mothers with young children to promote healthy eating and/or physical activity

\section{Nutrition interventions}

Campbell et al. (2004) ${ }^{(29)}$ : The intervention, Foodsmart, concerned interactive tailored nutrition education that took approximately 20-25 min to complete on the computer. The intervention included four main components: (i) a full-motion video soap opera; (ii) interactive 'infomercials'; (iii) tailored dietary feedback; and (iv) psychosocial feedback determined by baseline measurement

Havas et al. (1998) ${ }^{(25)}$ : The intervention, the Maryland WIC 5-A-Day Promotion Program, consisted of three components over a 6-month period: (i) three nutrition sessions conducted by peer educators; (ii) printed materials and visual reminders (a photo novella which served as a guidebook for group discussions and five clue cards; a booklet of recipes; a children's activity book focused on F\&V; a videotape showing children singing about F\&V; a refrigerator magnet with the programme's logo; and a calendar/reminder sheets containing information about future nutrition sessions); and (iii) direct mail (four different tailored letters accompanied by a tip sheet and a clue card)

Havas et al. (2003) ${ }^{(30)}$ : The multidimensional intervention Maryland WIC Food For Life (FFL) Program was targeted at participants' stages of change and included: (i) a 5 min video featuring enthusiastic participants from the pilot study; (ii) an attractive FFL brochure; (iii) individualized feedback on their baseline FFQ; (iv) a kick-off fair; (v) four 45 min workshops; (vi) newsletters; (vii) mail packets; (viii) personalized invitations; (ix) behaviour-reinforcing incentives; and (x) phone calls over a 6-month period

Herman et al. $(2008)^{(26)}$ : Participants in the two intervention sites were issued US\$10 worth of vouchers per week, in US\$1 units for the supermarket site and in US\$2 units for the farmers' market site, to buy produce of the participants' choice. Vouchers were issued bimonthly and could be spent over the ensuing 2-month period

\section{Nutrition and PA interventions}

Kinnunen et al. $(2007)^{(23)}$ : The intervention included individual counselling on PA (one primary counselling session and four booster sessions) and diet (one primary counselling session and three booster sessions in addition to the PA booster sessions) during five routine visits to a public health nurse and an option to attend exercise classes held once per week for 45-60 min

Leermakers et al. (1998) ${ }^{(31)}$ : A 6-month behavioural weight-loss intervention delivered via correspondence, which focused on low-fat/ low-calorie eating habits and increasing PA. This intervention included three components: (i) two group sessions; (ii) correspondence materials (sixteen written lessons about nutrition, exercise and behaviour change strategies); and (iii) telephone contact (weekly or biweekly)

Østbye et al. (2009) ${ }^{(33)}$ : Active Mothers Postpartum consisted of eight healthy eating sessions (Mom's Time Out (MTO) classes), ten PA group sessions (ACTIVMOMS classes) and six telephone-counselling sessions over a 9-month period. Participants were also provided a study notebook, pedometer and sport stroller

\section{PA interventions}

Cramp and Brawley $(2006)^{(36)}$ : Participants in the intervention condition received standard exercise training classes (SE) plus a groupmediated cognitive behavioural intervention (GMCB). SE consisted of an intensive phase (4 weeks) of exercise classes twice weekly immediately followed by 4 weeks of a home-based phase in which participants were encouraged to implement their own exercise regime. In addition, during the intensive phase, participants received six $20 \mathrm{~min}$ GMCB sessions consisting of self-regulatory skill training. During the home-based phase, one telephone contact was provided

Fahrenwald et al. (2004) (32): Moms on the Move consisted of three components: (i) provider counselling supplemented with (ii) an interactive trifolded, two-sided coloured brochure and (iii) four structured, biweekly provider-delivered telephone contacts to promote PA

Miller et al. (2002) ${ }^{(34)}$ : Group 2 received a print intervention. Group 3 received both the print intervention and an invitation to attend a meeting at their child care centre to discuss the development of local strategies for the promotion of PA among mothers of young children. This formed the basis for the development of intervention strategies (implemented through collaboration among participants, researchers and community organizations). In addition, group 3 received a PA directory with avenues for accessing information about PA opportunities in their local community; a telephone call was made after the discussion group meetings; and notice boards were displayed to encourage dissemination of information about local opportunities for PA

Watson et al. $(2005)^{(35)}$ : Nurses invited mothers in the intervention area to join pram walking groups. The pram walking groups were held once a week in a number of locations across the intervention area and were approximately $1 \mathrm{~h}$ in duration

WIC, Special Supplemental Nutrition Program for Women, Infants, and Children; F\&V, fruit and vegetables; PA, physical activity.

children, although with minor results (9-27\% attendance). To accommodate varying schedules of mothers, intervention sessions were repeated several times ${ }^{(25,30,33)}$ or the intervention was held at the mothers' preferred time of day $^{(35)}$. Furthermore, intervention setting and time schedules were adapted to WIC voucher pickup to maximize the limited opportunities for reaching mothers ${ }^{(25,30)}$. One group activity with mothers - pram walking - was organized to overcome social isolation among other things ${ }^{(35)}$.

\section{Explanations for attendance derived from additional attendance analyses}

Four studies had conducted explorative attendance research through a questionnaire and/or focus group discussions $^{(25,30,35)}$ (Table 4). Results showed that reasons for nonattendance were, for instance, a lack of interest or withdrawal from the organization that had implemented the intervention, $\mathrm{WIC}^{(25,30,37)}$. Moreover, some reasons mentioned for non-attendance were related to barriers specific to mothers, such as lack of child care or conflicting schedules ${ }^{(25,30,33,35)}$. Other reasons for non-attendance were more general, for example work or school conflicts, transport difficulties, sickness and mobility of participants ${ }^{(25,30,33,35,37)}$.

\section{Effectiveness}

Six out of twelve interventions did not result in positive significant effects (Table 5). Two interventions resulted in inconsistent (i.e. significant and non-significant) results on varying types of physical activity, eating behaviours and weight change ${ }^{(23,31)}$, and four resulted in no significant effects $^{(29,34,35)}$. Regarding the remaining six interventions, positive significant changes were reported on physical activity $^{(32,34,36)}$ and healthy eating ${ }^{(25,26,30)}$ in the short term (1-8 months).

Three studies conducted additional subgroup analyses ${ }^{(25,30,33)}$. No intervention effects were found in subgroup 
Table 3 Study characteristics

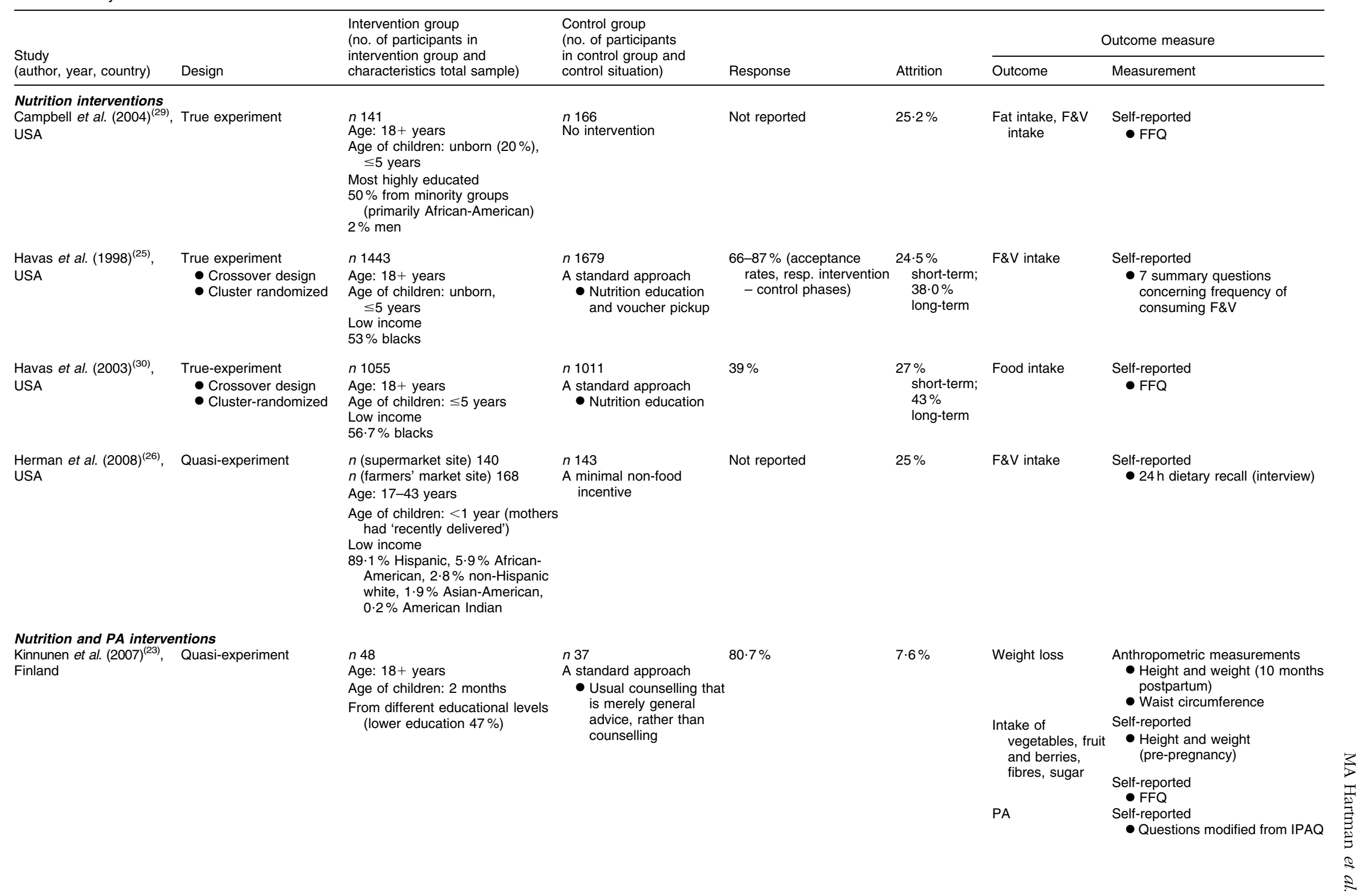




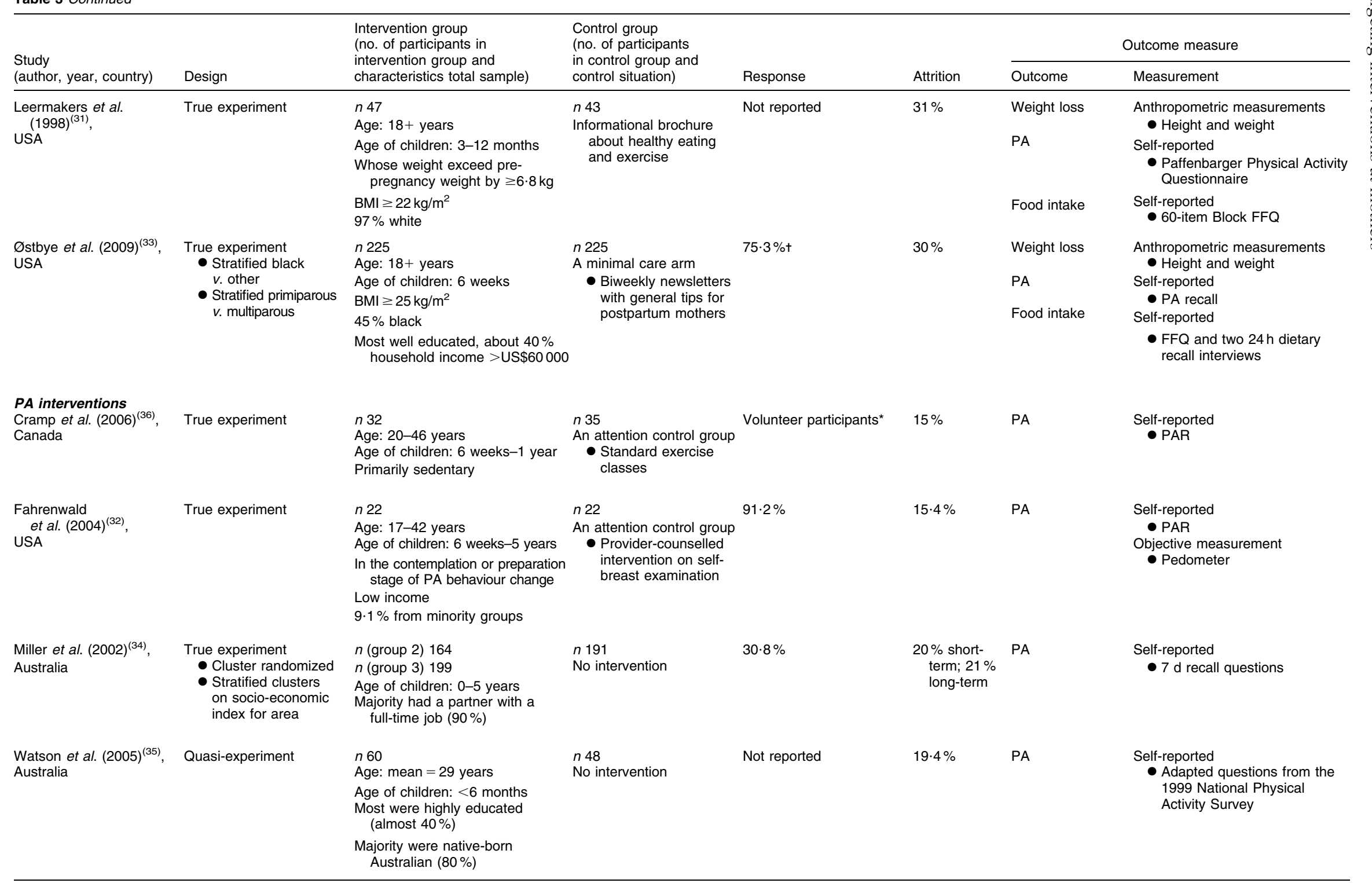

PA, physical activity; F\&V, fruit and vegetables; IPAQ, International Physical Activity Questionnaire; PAR, 7 d Physical Activity Recall.

+798 reached by phone, 136 not eligible, sixty-four did not complete baseline (=598 eligible), 148 refused; response calculated as $1-(148 / 598) \times 100=75 \cdot 3 \%$. 


\begin{tabular}{|c|c|}
\hline Study & Attendance \\
\hline $\begin{array}{l}\text { High attendance } \\
\text { Kinnunen et al. }(2007)^{(23)}\end{array}$ & $\begin{array}{l}92 \% \\
\text { - In the intervention group } 90 \% \text { of wome } \\
\text { participated in all PA counselling sessio } \\
\text { and } 94 \% \text { of women in all dietary couns } \\
\text { sessions } \\
\text { - On average, the women participated in } \\
\text { the } 5 \mathrm{PA} \text { counselling sessions and in } 3 \\
\text { the } 4 \text { dietary counselling sessions } \\
\text { - The average participation rate in the } \\
\text { (optional) group exercise sessions was } \\
50.7 \% \text { (sD } 28.5 \% \text { ) of the sessions avai } \\
\text { for each woman }\end{array}$ \\
\hline Cramp and Brawley (2006) $)^{(36)}$ & $\begin{array}{l}75 \% \\
\text { - Participants completed on average } 6 \text { of } \\
8 \text { postnatal exercise classes for a } 75 \%\end{array}$ \\
\hline
\end{tabular}
attendance rate

\section{Low attendance \\ Østbye et al. (2009) $)^{(33)}$}

Watson et al. (2005) ${ }^{(35)}$

60 out of 225 women attended 6 or more classes, 68 attended 1-5 classes, 97 attended 0 classes and a mean of 3.3 counselling calls more education and higher income than those who did not participate

$20 \%$

Intervention components targeted towards

mothers aimed to increase attendance

Explanations for non-attendance

Intervention setting was a child health clinic and

sessions were during routine visits

- The postpartum women were recruited through the child health care system, which is available to all families with children in every municipality in Finland and is funded by public tax revenue. Almost all (98\%) children attend these public child health clinics for regular check-ups

- The study protocol was implemented during five routine visits to a public health nurse at the child health clinic. These visits coincided with the child's age of 2, 3, 5, 6 and 10 months

Intervention setting nearby and for free

- The intensive phase was conducted at a community-based fitness facility (large commercial gym) which provided its facility free of charge

Child care provided

- Provided child care onsite for a nominal fee or the option to bring babies into class

Repeated intervention sessions

- ATIVMOMS classes were offered 2-6 times weekly, including Saturdays and different times of day, to accommodate various schedules of both working and stay-at-home mothers

- Participants attended a mean of $3 \cdot 8$ classes

- Those who took part in the classes were more likely to be older, white, married, had

- Over the 6 months 12 mothers (20\%) walked once a fortnight and 9 mothers (15\%) walked at least once a month

- $42 \%$ of intervention mothers joined a pram walking group less than once a month and $23 \%$ did not attend any

- At the start of the pram walking there was close to 40 mothers walking across 5 groups. After the 1st month the number dropped and remained below 25 mothers
- MTO sessions were offered each month at convenient times, usually adjacent to ACTIVMOMS classes

Mother and child activity on preferred time of day

- Mothers were asked their preferred time of day for a pram walking group

- Pram walking is designed to overcome the barriers to PA of child care, cost, time and social isolation
General explanations

- Coordinating schedules including the woman's own schedule (full-time work, school)

Explanations related to mothers in specific

- Problems securing child care

- Coordinating schedules including those of other children in the family

General explanations

- Mothers had gone back to work

Explanations related to mothers in specific

- Day of the week or time of day did not suit

- It was the baby's sleep time 


\begin{tabular}{|c|c|c|c|}
\hline Study & Attendance & $\begin{array}{l}\text { Intervention components targeted towards } \\
\text { mothers aimed to increase attendance }\end{array}$ & Explanations for non-attendance \\
\hline Havas et al. (1998) & $\begin{array}{l}19 \% \\
\text { - Attendance at the nutrition sessions varied } \\
\text { considerably by site } \\
\text { - Overall, } 19 \% \text { attended all } 3 \text { sessions, } 14 \% \\
\text { attended } 2 \text { sessions, } 20 \% \text { attended } \\
1 \text { session and } 46 \% \text { attended no sessions }\end{array}$ & $\begin{array}{l}\text { Repeated intervention sessions } \\
\text { - To accommodate the varying schedules of } \\
\text { the participants, the peer-led nutrition } \\
\text { sessions were repeated three times a } \\
\text { day ( } 9.00 \text { am, } 10.30 \text { am and } 1.00 \text { pm) for } \\
2 \text { days at each site } \\
\text { Intervention setting and time schedule adapted } \\
\text { to WIC voucher pickup } \\
\text { - At } 12 \text { sites, nutrition sessions were held prior } \\
\text { to the regular WIC voucher pickup days, } \\
\text { thereby allowing clients to pick up their } \\
\text { vouchers } 1 \text { or } 2 \text { days early and to avoid } \\
\text { crowds. At the other } 4 \text { sites, nutrition } \\
\text { sessions were held on days coinciding } \\
\text { with regular voucher pickup } \\
\text { Child care provided } \\
\text { - Provided child care by another peer educator } \\
\text { (usually) }\end{array}$ & $\begin{array}{l}\text { General explanations } \\
\text { - Work or school conflict } \\
\text { - Lack of interest/thought that nutrition } \\
\text { sessions would be boring and uninformative/ } \\
\text { a few preferred staying at home } \\
\text { - Withdrawal from WIC/thought that nutrition } \\
\text { sessions would be like WIC education } \\
\text { programmes } \\
\text { - Mobility and instability/no longer being in } \\
\text { WIC programme } \\
\text { - Not reached by reminder phone call } \\
\text { - Family or personal sickness } \\
\text { - Transportation difficulties/misconception that } \\
\text { attending the session would require an extra } \\
\text { trip to the WIC site (instead of picking up WIC } \\
\text { vouchers at the same time) } \\
\text { Explanations related to mothers in specific } \\
\text { - Lack of time/conflict with other activities/ } \\
\text { - Cheduling conflicts } \\
\text { - Child care difficulties }\end{array}$ \\
\hline Havas et al. $(2003)^{(30)}$ & $\begin{array}{l}9 \% \\
\text { - Attendance at the fairs/workshops varied } \\
\text { by site } \\
\text { - Approximately } 22 \% \text { attended } 1 \text { session, } 15 \% \\
\text { attended } 2 / 3 \text { sessions, } 9 \% \text { attended } \\
4 / 5 \text { sessions, while } 54 \% \text { attended none } \\
\text { - } 55 \% \text { of those aged } \geqslant 30 \text { attended at least } \\
\text { one session, v. } 45 \% \text { of those aged } 25-29 \\
\text { and } 37 \% \text { of those aged } 18-24(P<0 \cdot 001) \\
\text { - Blacks and whites were equally likely to } \\
\text { attend at least one session. } \\
\text { - } 39 \% \text { of those with less than a high-school } \\
\text { education attended at least one session, } \\
v .43 \% \text { of those with a high-school education } \\
\text { and } 51 \% \text { of those with some college } \\
(P=0 \cdot 008) \\
\text { - } 51 \% \text { of those who did not work attended at } \\
\text { least one session, } v .38 \% \text { of those who } \\
\text { worked }(P<0 \cdot 001)\end{array}$ & $\begin{array}{l}\text { Intervention setting and time schedule adapted } \\
\text { to WIC voucher pickup } \\
\text { - The programme minimized disruption of } \\
\text { WIC's procedures and maximized the limited } \\
\text { opportunities available for reaching } \\
\text { participants } \\
\text { Repeated intervention sessions } \\
\text { - In phase 2, five day-long fairs, allowing } \\
\text { participants to come at any time, covering } \\
\text { the same topics as phase } 1 \text { workshops } \\
\text { were held }\end{array}$ & $\begin{array}{l}\text { General explanations } \\
\text { - Many had assumed sessions would be } \\
\text { similar to WIC's and therefore did not attend } \\
\text { - Attending is a great logistical challenge given } \\
\text { the obstacles many participants faced such } \\
\text { as work, transportation and stresses or } \\
\text { inner-city life } \\
\text { - Change in the frequency of distribution of } \\
\text { WIC vouchers to every } 3 \text { months meant that } \\
\text { attending two-thirds of sessions required } \\
\text { special trips } \\
\text { Explanations related to mothers in specific } \\
\text { - Attending is a great logistical challenge given } \\
\text { the obstacles many participants faced such } \\
\text { as child-rearing responsibilities }\end{array}$ \\
\hline
\end{tabular}

PA, physical activity; WIC, Special Supplemental Nutrition Program for Women, Infants, and Children. 


\begin{tabular}{|c|c|}
\hline Study & Effectiveness \\
\hline $\begin{array}{l}\text { Significant e } \\
\text { Havas et al. } \\
\quad(1998)^{(25)}\end{array}$ & $\begin{array}{l}\text { ect on healthy eating } \\
\text { Short-term effect } \\
\text { - Mean increases in daily consumption } \\
\text { of } F \& V \text { were larger among intervention } \\
\text { participants }(0 \cdot 56 \text { (SD } 0 \cdot 11) \text { servings) } \\
V \text {. control participants }(0 \cdot 13 \text { (SD } 0 \cdot 17) \\
\text { servings; } P=0 \cdot 002) \\
\text { Effect on subgroups } \\
\text { - White women, women }<30 \text { years of age, } \\
\text { high-school graduates, married or not } \\
\text { working women showed significantly greater } \\
\text { increases in consumption } \\
\text { - Significant increases in consumption of F\&V } \\
\text { were found for intervention participants in } \\
\text { pre-contemplation, contemplation and } \\
\text { preparation stage at baseline, but not among } \\
\text { those in action and maintenance stages } \\
\text { Long-term effect } \\
\text { - Effects on F\&V remained significant at } 1 \text { year }\end{array}$ \\
\hline
\end{tabular}

- Effects on F\&V remained significant at 1 year

Key elements of a systematic

development which may contribute

to promoting lifestyle change

Intervention components targeted towards

1. Formative research

- Focus group discussions and central intercept

interviews

- Pilot study ${ }^{(38)}$

2. Theoretical framework

- SoC

3. Behaviour change strategies

- EDU, PC, SS, PE, GP, GS, RF, DS

4. Evidence-based

- Peer educators

5. Targeted to SES/ethnicity

- Peer educators ${ }^{(49)}$

\section{Havas et al. Short-term effect}

Difference in change in intervention participants $v$. controls was -1.62 (SD 0.33) $\%$ E from fat $(P<0.001), 0.4$ (SD 0.11$)$ servings of $\mathrm{F} \& \mathrm{~V}(P<0.001)$ and 1.01 SD 0.31$) \mathrm{g}$ fibre $(P=0.001)$

Effect on subgroups

- Significant differences between intervention and controls in both black and white participants

- Larger change among women aged $<30$ years and with at least high-schoo education

Long-term effect

- Effects remained after 1 year for fat $(-0.74$ (SD 0.38) \%E v. 0.87 (SD 0.41) \%E, $P=0.03$ ) and for $\mathrm{F} \& \mathrm{~V}$ consumption $(0.1$ (SD 0.13$)$ v. -0.32 (SD 0.14 ) servings, $P=0.03$ ), but not for fibre

\section{Formative research}

- Focus groups discussions

and central intercept interviews

- Pilot study

2. Theoretical framework

- TTM, SLT

3. Behaviour change strategies

- EDU, SS, PE, GS, ST

4. Targeted to SES/ethnicity

- Peer educators for assuring a culturally sensitive intervention

to low-income participants

- Newsletters had large fonts

and simple illustrations

- In phase 2: simplified

messages and a free bag

of food the fairs and workshops, made reminder mothers aimed to promote lifestyle change

Motivational appeals directed to mothers

- Two major motivational appeals were

used to stimulate adoption of the targeted behaviours: (i) set a good example for your children by eating more F\&V; and (ii) take care of yourself by eating more $\mathrm{F} \& \mathrm{~V}$ not only during pregnancy but also afterwards ${ }^{(38)}$

A photo novella with a mother role model as guidebook for nutrition sessions

- A photo novella, which featured

Ms. New-mother (a WIC participant) who modelled the activities leading to increased F\&V consumption, served as each participant's guidebook for writing thoughts about F\&V intake, setting goals, choosing behavioural strategies to achieve goals, and identifying and overcoming barriers ${ }^{(38)}$

Peer educators

- During nutrition sessions, peer educators guided participants through exercises in the photo novella, facilitated discussion and provided social support to help them achieve their goals ${ }^{(38)}$

Explanations for effectiveness

\section{Mediation}

- Changes in self-efficacy, attitudes, social support and knowledge of national consumption recommendations accounted for most of the intervention effect on increased consumption ${ }^{(39)}$

Attendance effectiveness relationship

- A strong relationship between attendance at nutrition sessions and changes in consumption was ound; the more sessions attended, the more F\&V servings consumed

\section{Peer educators}

Peer educators, of whom many had participated previously in WIC, taught a telephone calls and mailed educational packets
Attendance effectiveness relationship

- The more sessions attended, the greater the changes in intake. This applied to all three dietary variables 
Table 5 Continued

\begin{tabular}{|c|c|c|c|c|}
\hline Study & Effectiveness & $\begin{array}{l}\text { Key elements of a systematic } \\
\text { development which may contribute } \\
\text { to promoting lifestyle change }\end{array}$ & $\begin{array}{l}\text { Intervention components targeted towards } \\
\text { mothers aimed to promote lifestyle change }\end{array}$ & Explanations for effectiveness \\
\hline $\begin{array}{l}\text { Herman et al. } \\
\qquad(2008)^{(26)}\end{array}$ & $\begin{array}{l}\text { Short-term effect } \\
\text { - Difference in increases in servings of F\&V } \\
\text { per } 4186 \mathrm{~kJ} \text { of food consumed for } \\
\text { participants at the farmers' market site (from } \\
2 \cdot 2 \text { to } 3 \cdot 9 \text { ) and supermarket site (from } 2 \cdot 9 \text { to } \\
4 \cdot 1) \mathrm{v} \text {. control site (from } 2 \cdot 6 \text { to } 3 \cdot 0 ; F=9 \cdot 75 \text {; } \\
P<0 \cdot 001 \text { ) } \\
\text { Long-term effect } \\
\text { - Sustained increase in F\&V consumption at } \\
6 \text { months after intervention (farmers' market } \\
\text { and supermarket sites participants ate an } \\
\text { average of } 4 \cdot 0 \text { servings; participants at } \\
\text { control site reported an average of } 3 \cdot 1 ; \\
F=6 \cdot 66 ; P=0 \cdot 001 \text { ) } \\
\text { Note } \\
\text { - Increases in intake were primarily increases } \\
\text { in consumption of vegetables }\end{array}$ & $\begin{array}{l}\text { 1. Evidence-based } \\
\text { - Strategies to promote the } \\
\text { choice of targeted foods by } \\
\text { lowering their cost relative to } \\
\text { those of alternative foods } \\
\text { 2. Behaviour change strategies } \\
\text { - INC } \\
\text { 3. Targeted to SES/ethnicity } \\
\text { - Vouchers for F\&V for a } \\
\text { supermarket or a farmers' } \\
\text { market }\end{array}$ & & \\
\hline \multicolumn{5}{|c|}{ No significant effect on healthy eating } \\
\hline $\begin{array}{l}\text { Campbell } \\
\text { et al. } \\
(2004)^{(29)}\end{array}$ & $\begin{array}{l}\text { Short-term effect } \\
\text { - No significant differences between } \\
\text { intervention and control groups for } \\
\text { F\&V consumption and fat intake }\end{array}$ & $\begin{array}{l}\text { 1. Formative research } \\
\text { - Process and outcome } \\
\text { evaluation of the original } \\
\text { programme (Stamp Smart) } \\
\text { - Cognitive response } \\
\text { techniques }{ }^{(50)} \\
\text { 2. Theoretical framework } \\
\text { - SCT, TTM } \\
\text { 3. Behaviour change strategies } \\
\text { EDU, ML, FB } \\
\text { 4. Evidence-based } \\
\text { - Computer-based tailoring } \\
\text { 5. Targeted to SES/ethnicity } \\
\text { - Adapted language use } \\
\text { - Provided headphones and } \\
\text { audio narration }\end{array}$ & $\begin{array}{l}\text { Role modelling } \\
\text { - In the video soap opera the plot was } \\
\text { centred on a woman who pretends she is } \\
\text { pregnant to swindle money from the } \\
\text { estate of her former boyfriend. Initially the } \\
\text { woman learns about prenatal nutrition to } \\
\text { help her make her 'faked' pregnancy } \\
\text { appear to be genuine. Later, she } \\
\text { improves her diet for the sake of her baby } \\
\text { and husband-to-be }\end{array}$ & \\
\hline
\end{tabular}




\begin{tabular}{|c|c|c|c|}
\hline Study & Effectiveness & $\begin{array}{l}\text { Key elements of a systematic } \\
\text { development which may contribute } \\
\text { to promoting lifestyle change }\end{array}$ & $\begin{array}{l}\text { Intervention components targeted towards } \\
\text { mothers aimed to promote lifestyle change }\end{array}$ \\
\hline $\begin{array}{l}\text { Østbye et al. } \\
(2009)^{(33)}\end{array}$ & $\begin{array}{l}\text { Short-term effect on food intake } \\
\text { - Mean energy intake and \%E from fat } \\
\text { decreased in both groups, effects in groups } \\
\text { were not significantly different } \\
\text { - No differences on soda, sweetened drinks, fries } \\
\text { or chips, or F\&V per day, or fast food per week } \\
\text { Short-term effect on PA } \\
\text { - Both groups increased bouts of activity per } \\
\text { week and total minutes of activity per week, } \\
\text { effects in groups were not significantly } \\
\text { different } \\
\text { - No differences on sedentary behaviour } \\
\text { (TV hours per day) } \\
\text { Short-term effect on weight loss } \\
\text { - Women in both groups experienced modest } \\
\text { weight loss, effects in groups were not } \\
\text { significantly different } \\
\text { - No differences on return to pre-pregnancy } \\
\text { weight, \% weight loss, change in BMl } \\
\text { category, and proportion losing } \geq 4.5 \text { or } \\
1.0 \text { kg } \\
\text { Effect on subgroups } \\
\text { - No intervention effects were found in } \\
\text { subgroup analyses based on race, education, } \\
\text { parity or BMl category }\end{array}$ & $\begin{array}{l}\text { 1. Formative research } \\
\text { - Survey about interest and } \\
\text { preferences for weight } \\
\text { loss intervention }{ }^{(51)} \\
\text { - Pilot test of the intervention } \\
\text { materials } \\
\text { 2. Behaviour change strategies } \\
\text { - EDU, GP, DS, ST }\end{array}$ & $\begin{array}{l}\text { Exercise classes developed specifically for } \\
\text { postpartum wome } \\
\text { - ACTIVMOMS sessions included specific } \\
\text { exercises designed to enhance recovery } \\
\text { from pregnancy-related changes in body } \\
\text { structure and function. Using a stroller or } \\
\text { front-facing baby carrier, classes enabled } \\
\text { mothers to exercise with their babies. The } \\
\text { classes were taught by certified } \\
\text { postpartum exercise instructors } \\
\text { Discussion of barriers to PA and weight loss } \\
\text { in general common for the postpartum } \\
\text { period } \\
\text { - Barriers for exercise and PA shared by all } \\
\text { new mothers were emphasized and } \\
\text { discussed as a group } 52) \\
\text { - Educational activities helped women } \\
\text { develop strategies to overcome common } \\
\text { barriers to weight loss in the postpartum } \\
\text { period, such as lack of time, energy and } \\
\text { motivation }(52)\end{array}$ \\
\hline \multicolumn{4}{|c|}{ Significant effect on PA } \\
\hline $\begin{array}{l}\text { Cramp and } \\
\text { Brawley } \\
(2006)^{(36)}\end{array}$ & $\begin{array}{l}\text { Short-term effect } \\
\text { - Mean volume of moderate to vigorous PA } \\
\text { (=frequency } \times \text { duration) in intervention } \\
\text { group increased more (from } 126 \cdot 34 \\
\text { (SD } 152 \cdot 26) \text { to } 400 \cdot 38 \text { (SD } 288 \cdot 64) \text { ) than } \\
\text { in control group (from } 125 \cdot 32(\text { SD } 131 \cdot 25 \text { ) to } \\
222 \cdot 24 \text { (SD 177.37); } F(1,52)=8 \cdot 36, P<0 \cdot 01 \text { ) }\end{array}$ & $\begin{array}{l}\text { 1. Theoretical framework } \\
\text { SCT, SET } \\
\text { 2. Behaviour change strategies } \\
\text { GS, SM, ST, FB } \\
\text { 3. Evidence-based } \\
\text { - Theory-based intervention } \\
\text { framed in both SCT and group } \\
\text { dynamics } \\
\text { 4. Targeted to SES/ethnicity } \\
\text { - Free-of-charge use of a large } \\
\text { commercial gym }\end{array}$ & $\begin{array}{l}\text { Group counselling focused on how to } \\
\text { overcome postnatal-specific barriers to PA } \\
\text { - Focus on developing self-regulatory skills } \\
\text { for self-management of PA and to } \\
\text { overcome postnatal-specific barriers to } \\
\text { self-managed PA (e.g. goal setting, } \\
\text { defining barriers, brainstorm of barriers } \\
\text { and strategies to overcome barriers) } \\
\text { - Creation of a 'back-up' PA plan in the } \\
\text { event that mothers were unable to engage } \\
\text { in planned PA }\end{array}$ \\
\hline
\end{tabular}

Explanations for effectiveness

Attendance effectiveness relationship

- Class participation significantly associated with weight change in bivariate analysis $(P=0.01)$, but not with change in diet or PA

- Multivariable analysis controlling for age, race, education, income and baseline BMI attenuated effect of class participation on weight change $(P=0.57)$

- Completion of counselling calls not associated with weight or behaviour outcomes

\section{Mediation}

Self-regulatory efficacy partially mediated the relationship between intervention condition and post home-based PA (outcome expectations did not) ${ }^{(40)}$ 
Table 5 Continued

\begin{tabular}{|c|c|c|c|c|}
\hline Study & Effectiveness & $\begin{array}{l}\text { Key elements of a systematic } \\
\text { development which may contribute } \\
\text { to promoting lifestyle change }\end{array}$ & $\begin{array}{l}\text { Intervention components targeted towards } \\
\text { mothers aimed to promote lifestyle change }\end{array}$ & Explanations for effectiveness \\
\hline $\begin{array}{l}\text { Fahrenwald } \\
\text { et al. } \\
\quad(2004)^{(32)}\end{array}$ & $\begin{array}{l}\text { Short-term effect } \\
\text { - Significantly greater improvement in PA } \\
\text { behaviour in experimental group (effect size } \\
\geq 0 \cdot 80 \text { ) for each of the PAR indices } \\
\text { - Mean daily steps increased from } 5825 \cdot 03 \\
\text { (sD } 1867 \cdot 34 \text { ) to } 9180 \cdot 88 \text { (SD } 1700 \cdot 40 \text {; } \\
t(10)=6 \cdot 16, P<0 \cdot 001 \text { ) }\end{array}$ & $\begin{array}{l}\text { 1. Formative research } \\
\text { - Questionnaire examining } \\
\text { TTM constructs related to } \\
\text { PA of mothers }{ }^{(53)} \\
\text { 2. Theoretical framework } \\
\text { - TTM } \\
\text { 3. Behaviour change strategies } \\
\text { PC, SS, EDU, SM, GS } \\
\text { 4. Evidence-based } \\
\text { TTM interventions } \\
\text { 5. Targeted to SES/ethnicity } \\
\text { - 7th grade reading level } \\
\text { of the brochure }\end{array}$ & $\begin{array}{l}\text { A brochure with pros, cons and strategies } \\
\text { to overcome barriers to PA identified by } \\
\text { mother } \\
\text { - A brochure with examples of key pros and } \\
\text { cons to PA identified by WIC mothers, } \\
\text { and strategies to overcome frequently } \\
\text { cited barriers to PA (e.g. serving as a } \\
\text { positive role model for children was } \\
\text { emphasized; mothers were asked to think } \\
\text { about how their PA can benefit the whole } \\
\text { family) } \\
\text { Provider counselling } \\
\text { - The brochure was the guidebook during } \\
\text { provider counselling sessions. Mothers } \\
\text { had to identify two desired benefits of PA, } \\
\text { two personal barriers, and planned ways } \\
\text { to overcome these barriers }\end{array}$ & $\begin{array}{l}\text { No mediation } \\
\text { - Changes in PA outcome variables } \\
\text { were not mediated through } \\
\text { changes in stages of PA behaviour } \\
\text { change, exercise benefits/barriers, } \\
\text { self-efficacy for exercise, } \\
\text { processes of exercise adoption, } \\
\text { i.e. self-liberation, counter- } \\
\text { conditioning, environmental } \\
\text { re-evaluation, and social support } \\
\text { for exercise from family and } \\
\text { friends } 5 \text { (54) }\end{array}$ \\
\hline $\begin{array}{l}\text { Miller et al. } \\
\quad(2002)^{(34)} \\
\quad(\text { group 3) }\end{array}$ & $\begin{array}{l}\text { Short-term effect } \\
\text { - Group } 3 \text { women were significantly } \\
\text { more likely to meet guidelines at } \\
\text { post-intervention ( } 59 \cdot 9 \% \text { ) than group } 1 \\
\text { (control group) participants (46.3\%) } \\
\text { Long-term effect } \\
\text { - No effects in long term (5 months) }\end{array}$ & $\begin{array}{l}\text { 1. 'Formative research' } \\
\text { - Group 3: Discussion groups } \\
\text { about perceived barriers to PA } \\
\text { 2. Behaviour change strategies } \\
\text { - EDU, SS, CB } \\
\text { 3. Evidence-based } \\
\text { - Community-wide PA } \\
\text { interventions; targeting } \\
\text { multiple levels of influence }\end{array}$ & $\begin{array}{l}\text { A brochure with pros and cons and } \\
\text { strategies to overcome barriers to PA } \\
\text { identified by mothers } \\
\text { - See Miller group } 2 \\
\text { Discussion groups to explore barriers to PA } \\
\text { that formed basis for the development of } \\
\text { intervention strategies } \\
\text { - E.g. walking groups that met immediately } \\
\text { after delivering children to the child care } \\
\text { centre; sharing knowledge of existing } \\
\text { services in the local area; many active } \\
\text { women invited other mothers to join them } \\
\text { in their activities such as a tennis group in } \\
\text { which women rotated playing tennis and } \\
\text { child care } \\
\text { - E.g. project staff lobbying local leisure- } \\
\text { service providers to include or improve child } \\
\text { care services and to make their timetable of } \\
\text { activities more 'mom-friendly' (e.g. schedul- } \\
\text { ing aqua-aerobics classes at the same time } \\
\text { as children's learn-to-swim classes) } \\
\text { Note } \\
\text { - Developed strategies varied for } \\
\text { each child care centre }\end{array}$ & $\begin{array}{l}\text { Mediation } \\
\text { - Results suggest that partner } \\
\text { support and self-efficacy were act- } \\
\text { ing as mediators of PA behaviour } \\
\text { change resulting from the } \\
\text { intervention }\end{array}$ \\
\hline
\end{tabular}




\begin{tabular}{|c|c|c|c|c|}
\hline Study & Effectiveness & $\begin{array}{l}\text { Key elements of a systematic } \\
\text { development which may contribute } \\
\text { to promoting lifestyle change }\end{array}$ & $\begin{array}{l}\text { Intervention components targeted towards } \\
\text { mothers aimed to promote lifestyle change }\end{array}$ & Explanations for effectiveness \\
\hline \multicolumn{5}{|c|}{ No significant effect on PA } \\
\hline $\begin{array}{l}\text { Miller et al. } \\
(2002)^{(34)} \\
(\text { group 2) }\end{array}$ & $\begin{array}{l}\text { Short-term effect } \\
\text { - Compared with women in group } 1 \text { (control } \\
\text { group), group } 2 \text { women did not change PA } \\
\text { significantly, after controlling for age and PA } \\
\text { at baseline }\end{array}$ & $\begin{array}{l}\text { 1. Behaviour change strategies } \\
\text { - EDU }\end{array}$ & $\begin{array}{l}\text { A brochure with pros and cons and } \\
\text { strategies to overcome barriers to PA } \\
\text { identified by mothers } \\
\text { - Group } 2 \text { and } 3 \text { : A booklet containing } \\
\text { information about the benefits of PA, and } \\
\text { strategies for overcoming barriers that are } \\
\text { specific to mothers of young children }\end{array}$ & $\begin{array}{l}\text { No mediation } \\
\text { - Residual change in self-efficacy } \\
\text { was negative in both groups } 1 \\
\text { and } 2\end{array}$ \\
\hline $\begin{array}{l}\text { Watson } \\
\text { et al. } \\
(2005)^{(35)}\end{array}$ & $\begin{array}{l}\text { Short-term effect } \\
\text { - No significant increases in proportion of } \\
\text { women classified as performing adequate PA } \\
\text { in intervention as well as control group } \\
\text { - No significant difference in PA participation } \\
\text { between two groups }\end{array}$ & $\begin{array}{l}\text { 1. Behaviour change strategies } \\
\text { - GP, EDU (optional) }\end{array}$ & $\begin{array}{l}\text { Walking groups to overcome barriers of } \\
\text { mothers to PA } \\
\text { - Pram walking to overcome the barriers to PA } \\
\text { of child care, cost, time and social isolation } \\
\text { - Pram walking routes taking into considera- } \\
\text { tion: width and condition of the path; road } \\
\text { crossings on route; accessibility by public } \\
\text { transport; aesthetic nature of route; presence } \\
\text { of clean toilets and shade or shelter with a } \\
\text { seat for feeding, preferably at starting point }\end{array}$ & $\begin{array}{l}\text { Process evaluation: appreciation of } \\
\text { pram walking } \\
\text { - Mothers emphasized the } \\
\text { importance of walking routes that } \\
\text { met the needs of women with } \\
\text { babies and young children } \\
\text { - The majority of mothers joined a } \\
\text { pram walking group for exercise, to } \\
\text { get out of the house and meet } \\
\text { other postpartum women }\end{array}$ \\
\hline
\end{tabular}

General: PA, physical activity; F\&V, fruit and vegetables; \%E, percentage of energy; TV, television; PAR, 7 d Physical Activity Recall; SES, socio-economic status; WIC, Special Supplemental Nutrition Program for Women Infants, and Children.

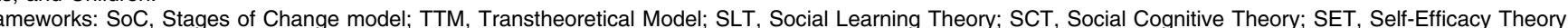

Behaviour change strategies: EDU, education; PC, discussing pros and cons; SS, providing/building social support; PE, peer educator; GP, guided practice; GS, goal setting; RF, reinforcement; DS, discussing strategies to overcome barriers; ST, skill training; INC, incentives; ML, modelling; FB, feedback; SM, self-monitoring; CB, capacity building. 
analyses based on race, education, parity or BMI category in one study ${ }^{(33)}$. Both studies of Havas et al. ${ }^{(25,30)}$ found that mothers younger than 30 years and with at least highschool education showed significantly greater increases in healthy eating. One study also found this pattern for married and non-working women ${ }^{(25)}$. Furthermore, white women showed significantly greater increases in fruit and vegetable consumption in one study ${ }^{(25)}$, while in the other study significant changes in healthy eating were found in both black and white participants ${ }^{(30)}$.

Of the three studies measuring long-term results ( 7 months to 1 year $)^{(25,30,34)}$, only Havas et al. ${ }^{(25)}$ reported long-term nutritional behaviour change. Henceforth, the description of the results will focus on short-term effects since these are available for all studies.

\section{Components witbin interventions which resulted in significant v. non-significant effects}

More systematically developed interventions were more likely to be effective (Table 5). Four interventions were developed using less than three out of five key components of a systematic development (i.e. formative research, theorybased, behaviour change strategies, evidence-based or targeted to socio-economic status/ethnicity), none resulting in significant effects ${ }^{(23,33-35)}$. Out of the other eight interventions using three key components or more, six interventions appeared to be effective in changing physical activity and healthy eating positively ${ }^{(25,26,30,32,34,36)}$.

Of the seven interventions directed at promoting healthy eating, three showed positive statistically significant results $^{(25,26,30)}$, of which only one was targeted at motivations of mothers ${ }^{(25)}$. The motivational appeals regarded 'set a good example for your children' and 'take care of yourself by eating more fruits and vegetables also after pregnancy,(38). In addition, more general behavioural change strategies such as the use of peer educators ${ }^{(25,30)}$ and role modelling ${ }^{(29)}$ were used in order to promote healthy eating.

In contrast, all eight interventions trying to promote physical activity included components targeted at mothers; mostly at overcoming barriers specific for mothers (e.g. physical changes, lack of time, social support or energy; Table 3). Five studies with components targeted at mothers did not show significant results on physical activity ${ }^{(23,31,33-35)}$. Of these studies, three were aimed at multiple behaviour change ${ }^{(23,31,33)}$. The two other interventions consisted of a single intervention; a brochure with tips for how to overcome barriers $^{(34)}$ or exercise - pram walking - groups ${ }^{(35)}$. These components were also elements in the three studies that showed significant results on physical activity ${ }^{(32,34,36)}$. For example, exercise classes were organized ${ }^{(36)}$ and brochures were used with tips including how to overcome mother-specific barriers ${ }^{(32,34)}$. However, these studies had additional (targeted) components (i.e. were multi-component) to promote physical activity (as a single behaviour). Both Cramp and Brawley ${ }^{(36)}$ and Fahrenwald et al. ${ }^{(32)}$ used in addition interactive counselling about perceived barriers and making plans on how to overcome these barriers. Furthermore, in the group III intervention of Miller et al. ${ }^{(34)}$ intervention mothers were asked to participate in discussion groups to explore their perceived barriers for physical activity. Outcomes formed the basis for the development of intervention strategies.

\section{Explanations for effectiveness derived from additional analyses}

Some studies investigated, and mostly found, evidence for the influence of effective interventions through mediators (mainly social support and self-efficacy) ${ }^{(34,39,40)}$ and attendance on physical activity or healthy eating ${ }^{(25,30,33)}$ (Table 5). In addition, Leermakers et $a l .{ }^{(31)}$ analysed the influence of adherence. The number of self-monitoring records returned was found to be significantly correlated with weight loss. Homework completion or telephone contact was not found to be associated with greater changes. No studies evaluated the targeted intervention components in relationship with effectiveness on physical activity. Regarding targeting, only the perception of pram walking groups by mothers was investigated in one study $^{(35)}$. Mothers emphasized the importance of having walking routes that met the needs of women with babies and young children. The majority of mothers who joined a pram walking group did so for exercise, to get out of the house and to meet other young mothers.

\section{Discussion}

The aim of the present review was to gain insight into targeted intervention components which may contribute to the attendance and effectiveness of interventions promoting physical activity and/or healthy eating to mothers with young children. Six out of the twelve studies included here measured attendance, of which two reported a high attendance. Especially the embedding of the intervention in routine visits to child health clinics seems to increase attendance rates. Cited explanations for nonattendance were general as well as mother-specific factors such as lack of interest, withdrawal from intervention setting and conflicting schedules.

Moreover, only six of the interventions reported statistically significant effects. Of these, three studies found positive effects on physical activity and three on healthy eating. Effective interventions directed at physical activity were multi-component and included such elements as counselling on mother-specific barriers or community involvement in intervention development and implementation. Interventions that effectively increased healthy eating did not all have components targeted at mothers. Only one study used mother-specific motivational appeals to promote healthy eating. No studies evaluated the targeted intervention components in relationship with effectiveness of the intervention in particular. 
The low attendance reported for most of the interventions shows the difficulty of reaching mothers of young children in programmes for promoting health behaviours - as mentioned by other authors ${ }^{(31,33,34,41,42)}$. This is also reflected in the large number of attempts to increase attendance with only minor results. For example, in spite of the fact that lack of time is frequently found to be a major barrier for mothers ${ }^{(43)}$, targeted intervention components such as repeated intervention sessions to overcome scheduling problems did not result in high attendance rates. This may be due to the fact that underlying factors causing time constraints among mothers are neglected in such a strategy (see also Watson et al. ${ }^{(35)}$ ). In a survey by Brown et $a l^{(18)}$, mothers mostly reported that having no time was due to commitments to children, housework and shopping. This may originate in restrictive role expectations towards mothers and the mother's perception of 'being a good mother ${ }^{(17,44)}$. Strategies that take these factors into account may provide opportunities for promoting attendance.

Furthermore, child care responsibilities and costs have been identified by mothers as two important barriers for attending weight-loss interventions ${ }^{(43,45)}$. However, studies that solved the problem of child care and had no costs did not consistently result in high attendance $e^{(25,35,36)}$. This may be due to a lack of interest for lifestyle change on the part of mothers. In a previous qualitative study investigating perceived barriers to attend weight-loss programmes, in addition to costs and child care, disinterested mothers perceived lack of time, family duties and conflicts with working schedule as barriers more compared with interested mothers ${ }^{(43)}$. In intervention studies with no costs and solutions for child care, indeed a lack of interest was mentioned as one of the reasons for a low attendance by actively recruited participants ${ }^{(25,37)}$. While another study with no costs and need for child care achieved a high attendance; in that study participants were recruited passively and thus were more likely to be highly motivated ${ }^{(36)}$. Therefore, motivating mothers, for example through mass media campaigns in order to get them physically active or eat healthier, seems a worthwhile point for reaching more mothers. Since the well-being of children is very important to mothers ${ }^{(17)}$, emphasizing that mothers are role models for their children might increase interest.

Because the well-being of children is important to mothers, it is reasonable that an intervention setting for the good of children will increase attendance. This is supported by the study of Kinnunen et al. ${ }^{(23)}$, whereby an intervention was embedded within routine visits to child health clinics resulting in a high attendance. Embedding the intervention in the routine of mother and child also gets round the problems of lack of time and child care responsibilities. Two other studies showed, however, that embedding the intervention within mothers' routine visits to an intervention setting might not contribute to attendance when there is withdrawal from this setting ${ }^{(25,30)}$.
With regard to the question on which intervention components contribute to the effectiveness on behaviour change, we found that all reviewed physical activity interventions included components targeted at mothers with young children. For physical activity, interactive counselling or discussion sessions about social and practical barriers perceived by mothers and making plans on how to overcome these barriers within the individual environment $^{(32,36)}$ or local community settings ${ }^{(34)}$ seems to promote physical activity among mothers. Such a strategy can address important constraints frequently cited by mothers, such as lack of time, energy, child care and social support, and obligations to other roles ${ }^{(8)}$.

Only one of the interventions aimed at improving healthy eating had components targeted towards mothers, while three out of four studies aimed at promoting healthy eating as a single behaviour showed statistically significant results. This one study used mother-specific motivational appeals rather than targeting mother-specific barriers. This may be because changing dietary behaviour is easier for mothers when compared with changing their physical activity pattern. In a previous study, young adult women reported that they saw a whole range of healthy eating behaviours as highly feasible but not many physical activity behaviours ${ }^{(46)}$. Mothers did perceive fruit and vegetable consumption to be more feasible compared with non-mothers although they perceived leisure-time physical activity, physical activity for transport purposes and incidental physical activity as less feasible compared with women with no children.

Definite conclusions about which components may contribute to intervention effectiveness cannot be drawn, however, from the studies included in the current review since the actual contribution of components targeted at mothers of young children on the effectiveness has not been evaluated. Only the appreciation of pram walking groups was found by Watson et $a l .{ }^{(35)}$. Therefore, the effectiveness on physical activity and on healthy eating may also depend on the multi-component character or the systematic development of most of the effective interventions included in the review. Furthermore, theory-based developed interventions aimed at reaching intervention effects on physical activity or healthy eating through theoretical constructs (i.e. mediators) that are important for mothers, such as self-efficacy and social support, might increase effectiveness ${ }^{(34,39,40)}$. There is a need for more process evaluations which focus on the question of how intervention effects are obtained.

Furthermore, in order to disseminate the use of interventions, it is necessary to know to which subpopulations the programme effects can be generalized. Notable was that while all studies with mainly low-income or ethnic minority participants in the present review had targeted their interventions to these low-income and/or minority groups $^{(25,26,29,30,32)}$, only two studies performed subgroup analyses $^{(25,30)}$. More of such analyses are needed to gain insight into the effectiveness of interventions for specific 
target groups. In accordance, future studies that conduct subgroup analysis for mothers $v$. non-mothers can give more information about the generalizability of interventions directed at women in general towards mothers in particular.

The main limitations of the present review study are the limited amount of eligible studies found, that informationgathering was restricted to printed material, and the low comparability of the studies. For instance, studies differed on the quality of design, sample size and outcome measurements. For this reason, the choice for descriptive analyses was made and no meta-analyses could be done. Nevertheless, these descriptive analyses can be useful for intervention practice since they could provide examples for future intervention development and implementation. For health promotion, it might be worthwhile also to include study designs other than randomized controlled trials (i.e. true experiments) in a review. The use of randomized controlled trials is not always appropriate to evaluate health promotion interventions ${ }^{(47)}$; consequently reviewing interventions evaluated in other designs such as quasi-experiments can be more applicable for practice.

\section{Conclusions}

Although promoting weight control among new mothers is valuable in obesity prevention, the number of experimental intervention studies for promoting physical activity and healthy eating among new mothers is limited. Nevertheless, first recommendations useful for intervention practice can be set. Opportunities for increasing attendance of future interventions directed at mothers are, for example, embedding interventions into the mother and child routine, addressing the restricting role expectations for mothers, or motivating mothers for lifestyle change activities first. In addition, systematic development and multi-component interventions seem important to the success of these interventions. Moreover, chances for promoting physical activity among mothers are targeting the methods used regarding mother-specific barriers. Little evidence is found yet, however, to suggest the need for and recommend ways of targeting at new mothers for stimulating healthy eating. More research is required to substantiate the findings, especially with regard to the promotion of healthy eating. Process and subgroup analyses can contribute more insight into how interventions work and for which subgroups.

\section{Acknowledgements}

Source of funding: This study was funded by ZonMw, The Netherlands organization for health research and development. Conflicts of interest: There are no conflicts of interest. Author contributions: M.A.H. performed the literature search, data extraction, data analysis and drafted the manuscript. K.H. helped in determining the eligibility of articles in cases of doubt. K.S. conceived the study. K.H. and K.S. helped to draft the manuscript. All authors contributed to the design of the analysis. All authors read and approved the final manuscript.

\section{References}

1. Williamson DF, Kahn HS, Remington PL et al. (1990) The 10 -year incidence of overweight and major weight gain in US adults. Arch Intern Med 150, 665-672.

2. Mokdad AH, Serdula MK, Dietz WH et al. (1999) The spread of the obesity epidemic in the United States, 1991-1998. JAMA 282, 1519-1522.

3. Wendel-Vos GCW, Nooyens ACJ \& Schuit AJ (2004) The Contribution of Lifestyle to Weight Gain Among Young Adults. Report no. 260301001/2004. Bilthoven: RIVM.

4. Linne Y, Dye L, Barkeling B et al. (2004) Long-term weight development in women: a 15-year follow-up of the effects of pregnancy. Obes Res 12, 1166-1178.

5. Rooney BL, Schauberger CW \& Mathiason MA (2005) Impact of perinatal weight change on long-term obesity and obesity-related illnesses. Obstet Gynecol 106, $1349-1356$.

6. Rossner S \& Ohlin A (1995) Pregnancy as a risk factor for obesity: lessons from the Stockholm Pregnancy and Weight Development Study. Obes Res 3, Suppl. 2, 267s-275s.

7. Ball K, Brown W \& Crawford D (2002) Who does not gain weight? Prevalence and predictors of weight maintenance in young women. Int $J$ Obes Relat Metab Disord 26, 1570-1578.

8. Bellows-Riecken KH \& Rhodes RE (2008) A birth of inactivity? A review of physical activity and parenthood. Prev Med 46, 99-110.

9. Sternfeld B, Ainsworth BE \& Quesenberry CP (1999) Physical activity patterns in a diverse population of women. Prev Med 28, 313-323.

10. Nomaguchi KM \& Bianchi SM (2004) Exercise time: gender differences in the effects of marriage, parenthood, and employment. J Marriage Fam 66, 413-430.

11. Cuco G, Fernandez-Ballart J, Sala J et al. (2006) Dietary patterns and associated lifestyles in preconception, pregnancy and postpartum. Eur J Clin Nutr 60, 364-371.

12. George GC, Hanss-Nuss H, Milani TJ et al. (2005) Food choices of low-income women during pregnancy and postpartum. J Am Diet Assoc 105, 899-907.

13. Olson CM (2005) Tracking of food choices across the transition to motherhood. J Nutr Educ Behav 37, 129-136.

14. Harris HE, Ellison GT, Holliday M et al. (1997) The impact of pregnancy on the long-term weight gain of primiparous women in England. Int J Obes Relat Metab Disord 21, $747-755$.

15. Olson CM, Strawderman MS, Hinton PS et al. (2003) Gestational weight gain and postpartum behaviors associated with weight change from early pregnancy to $1 \mathrm{y}$ postpartum. Int J Obes Relat Metab Disord 27, 117-127.

16. Amorim A, Linne Y \& Lourenco P (2007) Diet or exercise, or both, for weight reduction in women after childbirth. Cochrane Database Syst Rev issue 3, CD005627.

17. Lewis B \& Ridge D (2005) Mothers reframing physical activity: family oriented politicism, transgression and contested expertise in Australia. Soc Sci Med 60, 2295-2306.

18. Brown PR, Brown WJ, Miller YD et al. (2001) Perceived constraints and social support for active leisure among mothers with young children. Leisure Sci 23, 131-144.

19. Bartholomew L, Parcel G, Kok G et al. (2006) Planning Health Promotion Programs: Intervention Mapping. San Francisco, CA: Jossey-Bass. 
20. Dewey KG (1998) Effects of maternal caloric restriction and exercise during lactation. J Nutr 128, 2 Suppl., 386S-389S.

21. Keller C, Records K, Ainsworth B et al. (2008) Interventions for weight management in postpartum women. $J$ Obstet Gynecol Neonatal Nurs 37, 71-79.

22. Kuhlmann AK, Dietz PM, Galavotti C et al. (2008) Weightmanagement interventions for pregnant or postpartum women. Am J Prev Med 34, 523-528.

23. Kinnunen TI, Pasanen M, Aittasalo M et al. (2007) Reducing postpartum weight retention - a pilot trial in primary health care. Nutr J 6, 21.

24. Kinnunen TI, Aittasalo M, Koponen P et al. (2008) Feasibility of a controlled trial aiming to prevent excessive pregnancy-related weight gain in primary health care. $B M C$ Pregnancy Childbirth 8, 37.

25. Havas S, Anliker J, Damron D et al. (1998) Final results of the Maryland WIC 5-A-Day Promotion Program. Am J Public Health 88, 1161-1167.

26. Herman DR, Harrison GG, Afifi AA et al. (2008) Effect of a targeted subsidy on intake of fruits and vegetables among low-income women in the Special Supplemental Nutrition Program for Women, Infants, and Children. Am J Public Health 98, 98-105.

27. Feldman RH, Damron D, Anliker J et al. (2000) The effect of the Maryland WIC 5-A-Day promotion program on participants' stages of change for fruit and vegetable consumption. Health Educ Behav 27, 649-663.

28. Herman DR, Harrison GG \& Jenks E (2006) Choices made by low-income women provided with an economic supplement for fresh fruit and vegetable purchase. $J$ Am Diet Assoc 106, 740-744.

29. Campbell MK, Carbone E, Honess-Morreale L et al. (2004) Randomized trial of a tailored nutrition education CD-ROM program for women receiving food assistance. J Nutr Educ Behav 36, 58-66.

30. Havas S, Anliker J, Greenberg D et al. (2003) Final results of the Maryland WIC Food for Life Program. Prev Med 37, 406-416.

31. Leermakers EA, Anglin K \& Wing RR (1998) Reducing postpartum weight retention through a correspondence intervention. Int J Obes Relat Metab Disord 22, 1103-1109.

32. Fahrenwald NL, Atwood JR, Walker SN et al. (2004) A randomized pilot test of 'Moms on the Move': a physical activity intervention for WIC mothers. Ann Behav Med 27, 82-90.

33. Østbye T, Krause KM, Lovelady CA et al. (2009) Active Mothers Postpartum: a randomized controlled weight-loss intervention trial. Am J Prev Med 37, 173-180.

34. Miller YD, Trost SG \& Brown WJ (2002) Mediators of physical activity behavior change among women with young children. Am J Prev Med 23, 98-103.

35. Watson N, Milat AJ, Thomas M et al. (2005) The feasibility and effectiveness of pram walking groups for postpartum women in western Sydney. Health Promot J Aust 16, 93-99.

36. Cramp AG \& Brawley LR (2006) Moms in motion: a groupmediated cognitive-behavioral physical activity intervention. Int J Behav Nutr Phys Act 3, 23.

37. Damron D, Langenberg P, Anliker J et al. (1999) Factors associated with attendance in a voluntary nutrition education program. Am J Health Promot 13, 268-275.
38. Havas S, Damron D, Treiman K et al. (1997) The Maryland WIC 5 a day promotion program pilot study: rationale, results, and lessons learned. J Nutr Educ 29, 343-350.

39. Langenberg P, Ballesteros M, Feldman R et al. (2000) Psychosocial factors and intervention-associated changes in those factors as correlates of change in fruit and vegetable consumption in the Maryland WIC 5 A Day Promotion Program. Ann Behav Med 22, 307-315.

40. Cramp AG \& Brawley LR (2009) Sustaining self-regulatory efficacy and psychological outcome expectations for postnatal exercise: effects of a group-mediated cognitive behavioural intervention. Br J Health Psychol 14, 595-611.

41. Gore SA, Brown DM \& West DS (2003) The role of postpartum weight retention in obesity among women: a review of the evidence. Ann Behav Med 26, 149-159.

42. Cody R \& Lee C (1999) Development and evaluation of a pilot program to promote exercise among mothers of preschool children. Int J Behav Med 6, 13-29.

43. French SA, Jeffery RW, Story $M$ et al. (1998) Perceived barriers to and incentives for participation in a weight-loss program among low-income women in WIC. J Am Diet Assoc 98, 79-81.

44. Miller YD \& Brown WJ (2005) Determinants of active leisure for women with young children: an 'ethic of care' prevails. Leisure Sci 27, 405-420.

45. Setse R, Grogan R, Cooper LA et al. (2008) Weight loss programs for urban-based, postpartum African-American women: perceived barriers and preferred components. Matern Child Health J 12, 119-127.

46. Ball K, Crawford D \& Warren N (2004) How feasible are healthy eating and physical activity for young women? Public Health Nutr 7, 433-441.

47. Victora CG, Habicht JP \& Bryce J (2004) Evidence-based public health: moving beyond randomized trials. $A m J$ Public Health 94, 400-405.

48. Treiman K, Freimuth V, Damron D et al. (1996) Attitudes and behaviors related to fruits and vegetables among low-income women in the WIC program. J Nutr Educ 28, 149-156.

49. Havas S, Anliker J, Damron D et al. (2000) Uses of process evaluation in the Maryland WIC 5-a-day promotion program. Health Educ Behav 27, 254-263.

50. Carbone ET, Campbell MK \& Honess-Morreale L (2002) Use of cognitive interview techniques in the development of nutrition surveys and interactive nutrition messages for low-income populations. I Am Diet Assoc 102, 690-696.

51. Østbye T, McBride C, Mark-Wahnefried W et al. (2003) Interest in healthy diet and physical activity interventions peripartum among female partners of active duty military. Mil Med 168, 320-325.

52. Østbye T, Krause KM, Brouwer RJ et al. (2008) Active Mothers Postpartum (AMP): rationale, design, and baseline characteristics. J Womens Health (Larchmt) 17, 1567-1575.

53. Fahrenwald NL \& Walker SN (2003) Application of the Transtheoretical Model of behavior change to the physical activity behavior of WIC mothers. Public Health Nurs 20, 307-317.

54. Fahrenwald NL, Atwood JR \& Johnson DR (2005) Mediator analysis of Moms on the Move. West J Nurs Res 27, 271-291. 